\title{
Astrocyte and Glutamate Markers in the Superficial, Deep, and White Matter Layers of the Anterior Cingulate Gyrus in Schizophrenia
}

\author{
Pavel Katsel', William Byne ${ }^{1,2}$, Panos Roussos ${ }^{1,2}$, Weilun Tan', Larry Siever ${ }^{1,2}$ and Vahram Haroutunian*,1,2 \\ 'Department of Psychiatry, The Mount Sinai School of Medicine, New York, NY, USA; ${ }^{J} J$ Peters VA Medical Center, Bronx, NY, USA
}

\begin{abstract}
Most studies of the neurobiology of schizophrenia have focused on neurotransmitter systems, their receptors, and downstream effectors. Recent evidence suggests that it is no longer tenable to consider neurons and their functions independently of the glia that interact with them. Although astrocytes have been viewed as harbingers of neuronal injury and CNS stress, their principal functions include maintenance of glutamate homeostasis and recycling, mediation of saltatory conduction, and even direct neurotransmission. Results of studies of astrocytes in schizophrenia have been variable, in part because of the assessment of single and not necessarily universal markers and/or assessment of non-discrete brain regions. We used laser capture microdissection to study three distinct partitions of the anterior cingulate gyrus (layers I-III, IV-VI, and the underlying white matter) in the brains of I 8 well-characterized persons with schizophrenia and 21 unaffected comparison controls. We studied the mRNA expression of nine specific markers known to be localized to astrocytes. The expression of astrocyte markers was not altered in the superficial layers or the underlying white matter of the cingulate cortex of persons with schizophrenia. However, the expression of some astrocyte markers (diodinase type II, aquaporin-4, SI00 $\beta$, glutaminase, excitatory amino-acid transporter 2, and thrombospondin), but not of others (aldehyde dehydrogenase I family member LI, glial fibrillary acidic protein, and vimentin) was significantly reduced in the deep layers of the anterior cingulate gyrus. These findings suggest that a subset of astrocytes localized to specific cortical layers is adversely affected in schizophrenia and raise the possibility of glutamatergic dyshomeostasis in selected neuronal populations.

Neuropsychopharmacology (20 I I) 36, I I7I-I I77; doi:I0.1038/npp.20 10.252; published online 26 January 20 I I
\end{abstract}

Keywords: astrocytes; cortical layers; postmortem; mRNA; schizophrenia

\section{INTRODUCTION}

Neurobiological studies of schizophrenia (SZ) have identified a myriad of abnormalities, some of which have been relatively consistently replicated, whereas others have been inconsistent (Bernstein et al, 2009). Among the inconsistent results are those from studies that have focused on central nervous system gliosis, astrocytes, and astrocytosis. Initial studies suggested astrocytosis in multiple brain regions of functional importance to SZ (Stevens et al, 1988; Stevens, 1982); however, later studies found few, if any, changes in astrocytes or reductions in the numbers or expression levels of astrocyte markers (Webster et al, 2005; Schnieder and Dwork, 2011). In general, the focus on astrocytes was based

*Correspondence: Dr $\vee$ Haroutunian, Department of Psychiatry, The Mount Sinai School of Medicine, Room 4F-33, 130 West Kingsbridge Road, New York, Bronx NY 10468, USA.

Tel.: + 7 18 5849000 ext 6082, Fax: + 7183659622 ,

E-mail: Vahram.haroutunian@mssm.edu

Received 12 November 2010; revised 20 December 2010; accepted

21 December 2010 on an interest in astrocytosis as a harbinger of neurodegenerative events, rather than primary sources of pathology in their own right. To be sure, astrocytes serve a significant and indisputable function in the CNS response to injury and physiological stress. However, astrocytes have been found to have significantly broader functional roles in the CNS that include not only activities associated with neuroprotection and support, but also functions that involve maintenance of homeostasis, glutamate recycling, mediation of saltatory conduction, and even direct neurotransmission, to name but a few (Zhang and Barres, 2010). All of these myriad functions have clear relevance to SZ; not the least of which are the roles astrocytes played by in glutamate homeostasis and recycling (Zhang and Barres, 2010; Barres, 2008; Kenakin, 2002).

The associations of glutamatergic abnormalities with SZ are now well established (Bernstein et al, 2009). Although significant disparities exist in the specific glutamate pathways and glutamatergic receptor involvement in SZ, the importance of glutamatergic signaling in SZ is well established (Krystal et al, 1998; Harrison and Weinberger, 
2004; Dracheva et al, 2001; Gluck et al, 2002; Javitt, 2007). When glutamate is released into the synaptic cleft, it acts on postsynaptic ionotropic and/or metabotropic receptors. The functions of glutamate are then terminated by its uptake into astrocytes by excitatory amino-acid transporters (EAAT) where it is enzymatically converted to the glutamate precursor, glutamine, by the enzyme glutamine synthase (GS)(Gluck et al, 2002). Glutamine released from astrocytes is then taken up by neurons and recycled to glutamate by the enzyme phosphate-activated glutaminase (GL). Different studies in SZ have frequently, but not always (Bauer et al, 2008), found significant abnormalities in the abundance of transporters (eg, EAAT2) and in the levels or activities of GS and GA (Steffek et al, 2008; Bruneau et al, 2005; Toro et al, 2006; Huerta et al, 2006; Lauriat et al, 2006; Bauer et al, 2010). As GS and EAAT2 are localized to perisynaptic astrocytes, reductions in EAAT2 and GS imply abnormalities at the level of astrocytes that could involve their dysfunction or reduced numbers (Bernstein et al, 2009). Thus, in the context of glutamate neurotransmission, astrocytes have an indispensable role (Steffek et al, 2008; Barradas et al, 2000; Halassa et al, 2007; Barres, 2008; Zhang and Barres, 2010) that is at least in part independent of their other biological functions, including activation and involvement in neurodegeneration and neural-scar formation, energy metabolism and glucose and potassium homeostasis, and cholesterol biosynthesis.

Generally, studies of astrocytes in SZ have focused on only a few individual astrocyte markers, such as glial fibrillary acidic protein (GFAP) and $S 100 \beta$ (Arnold et al, 1996; Falke et al, 2000; Arnold et al, 1998; Steiner et al, 2008). The recent identification of multiple, and importantly at times non-overlapping, astrocyte-associated proteins and transcripts has reinforced the view of considerable diversity in astrocyte populations (Cahoy et al, 2008; Zhang and
Barres, 2010), raising the possibility that such diversity may also exist in their disease association, distribution, and function.

In this study, we measured the expression of multiple astrocyte and glutamate markers in SZ using a cortical layer and white-matter-specific approach. We took advantage of recently published data on the transcriptome of astrocytes (Cahoy et al, 2008) and selected for measurement mRNA transcripts that were preferentially and robustly expressed in astrocytes. The anterior cingulate gyrus was selected for study because of multiple reports of SZ-associated cytoarchitectural, imaging, and neurobiological vulnerability of this brain region (Haroutunian et al, 2007; Benes and Bird, 1987; Haznedar et al, 2004; Wang et al, 2010). To determine whether the glutamatergic abnormalities noted in SZ were cortical layer specific and more closely associated with particular astrocyte markers, we also measured the expression levels of GL, GS, and EAAT2 transcripts in the same anatomical regions.

\section{METHODS}

\section{Subjects}

Postmortem brain-tissue specimens were collected and banked for use in research after consent by the next of kin or other legally authorized representatives. All subjects (Table 1) died of natural causes with no history of licit or illicit drug abuse, neuropathology, or neurological disease. The mean age, postmortem interval (PMI), tissue $\mathrm{pH}$, and sex distributions of the subjects are shown in Table 1. Every brain was examined neuropathologically according to the structured procedures described by CERAD (Mirra et al, 1991; Purohit et al, 1998), and none of the selected brains exhibited any discernable neuropathology. Patients were

Table I Demographical and Other Characteristics of the Study Sample.

\begin{tabular}{|c|c|c|c|c|c|c|}
\hline & $\mathbf{N}$ & Sex & Age & pH & PMI, min & $\mathbf{R I N}$ \\
\hline $\mathrm{NC}$ & 21 & IIF IOM & $76.5(2.44)$ & $6.62(0.06)$ & $584.2(101)$ & $6.78(0.1)$ \\
\hline $\mathrm{SZ}$ & 18 & $8 \mathrm{~F} \mid \mathrm{OM}$ & $78.1(1.90)$ & $6.56(0.04)$ & $774.9(7 \mathrm{I})$ & $6.45(0.2)$ \\
\hline \multicolumn{7}{|c|}{ Total dissection area $\left(\mathrm{mm}^{2}\right)$} \\
\hline & Superficial layers & & Deep layers & & Underlying white matter & \\
\hline NC & | $6.02(0.96)$ & & $16.19(1.03)$ & & $23.34(0.56)$ & \\
\hline $\mathrm{SZ}$ & $17.82(1.39)$ & & I $6.43(0.76)$ & & $24.30(0.84)$ & \\
\hline \multicolumn{7}{|c|}{ Causes of death } \\
\hline \multirow[t]{4}{*}{$\mathrm{NL}$} & Myocardial infarction & & 3 & Arrhythmia & & 2 \\
\hline & Renal disease & & 2 & Pneumonia & & 2 \\
\hline & Cancer & & 3 & Congestive heart disease & & 2 \\
\hline & Atherosclerotic heart disease & & 4 & Sepsis & & 2 \\
\hline \multirow[t]{4}{*}{ SZ } & Myocardial infarction & & 2 & Congestive heart disease & & 2 \\
\hline & Renal disease & & 1 & Pneumonia & & 3 \\
\hline & Cancer & & 2 & Sepsis & & I \\
\hline & Atherosclerotic heart disease & & 7 & & & \\
\hline
\end{tabular}

Mean (SEM). 
diagnosed antemortem according to Diagnostic and Statistical Manual of Mental Disorders, Fourth Edition (DSM-III or IV) criteria as described (Davidson et al, 1995; Harvey et al, 1998). Controls (nursing home and independent living facility residents) showed no neurological or neuropsychiatric diseases (Purohit et al, 1998). Diagnostic and postmortem consent procedures were approved by the Mount Sinai, Bronx VA, and Pilgrim Psychiatric Center IRBs. The studied cases were selected from a large group of controls $(N=92)$ and persons with SZ $(N=254)$ to meet strict criteria with respect to natural causes of death, absence of discernable neuropathology, lack of comorbid psychopathology, short postmortem intervals, brain tissue $\mathrm{pH}>6.0$, and high-quality RNA.

\section{Tissue Handling, Sectioning, Dissection, and RNA Isolation}

The protocols used were similar to those described in detail recently (Dracheva et al, 2008; Byne et al, 2008). Blocks of tissue were sectioned serially in the coronal plane at a thickness of $20 \mu \mathrm{m}$ on a cryostat. For anatomical localization, the first of each series of five sections was mounted onto a regular glass slide, stained with thionin, and coverslipped. The next set of four sections was cut and mounted onto penfoil polymer (PEN) microdissection slides and stored at $-80^{\circ} \mathrm{C}$ until use. The anterior cingulate cortex for this study was defined as the region of the cingulate gyrus (Brodmann area 24/32) that was evident from the decussation (genu) of the corpus callosum and extending caudally for $1-1.5 \mathrm{~cm}$. The lower border of layer III and the layer VI/white matter border were identified microscopically (using a Leica binocular dissecting scope with zoom magnification $(6.3-40 \times))$ on the stained and coverslipped slide adjacent to the section being dissected from the penfoil slides and marked by an ultrafine-tipped pen. This section was then used as a guide to mark the dissection borders on the back of the penfoil slide designated for laser capture microdissection. The identified PEN slides were removed from the freezer, immediately fixed in $100 \%$ ethanol for $1 \mathrm{~min}$, and then rehydrated in ethanol/water graded series $(95,75$, and $50 \% ; 1$ min each). Sections were then stained for $\sim 30 \mathrm{~s}$ in $1 \%$ Thionin in $0.05 \mathrm{M} \mathrm{NaCH}_{3} \mathrm{COO}$ buffer, $\mathrm{pH} 4.5$, washed in water for $30 \mathrm{~s}$, dehydrated $(75,95$, and $100 \%$ ethanol, 1 min each), dried for $1 \mathrm{~min}$, and immediately used for microdissection. All solutions were prepared with DEPC-treated water. Laser Capture Microdissection (LCM) was performed using a Leica AS LMD system (Leica Microsystems, Bannockburn, IL). Every effort was made to maintain a near surgical aseptic setting when handling tissue blocks, slides, and tissue sections for LCM to protect against RNA degradation by RNAses. Tissue dissected from four to six slides was used for this study.

Total RNA was extracted using the PicoPure RNA isolation Kit (Molecular Devices, Sunnyvale, CA). RNA quality and concentration were evaluated using BioAnalyzer (Agilent Technologies, Santa Clara, CA). Only samples with RNA integrity number (RIN) $\geqslant 6$ were used (Table 2). Equal amounts of isolated RNA were used for the RT reactions for

Table 2 Description of TaqMan Assays Used in the Study

\begin{tabular}{|c|c|c|c|c|c|c|}
\hline Target & Assay ID & Species & NCBI ref. & Exon/exon boundary & Assay location & Isoform specificity \\
\hline ALDHILI & Hs0020l836_ml & human & NM_0I2190.2 & $14 \mid 15$ & 1888 & 4 major isoforms \\
\hline AQP4 & Hs00242342_ml & human & NM_001650.4 & 213 & 507 & 3 major isoforms \\
\hline GFAP & Hs00909236_ml & human & NM_002055.3 & $4 \mid 5$ & 841 & 2 isoforms \\
\hline GLS & Hs00248I63_ml & human & NM_0I4905.3 & $11 \mid 12$ & 1515 & 2 major isoforms \\
\hline SLCIA2/ EAAT2 & $\mathrm{Hs}$ Oll02423_ml & human & NM_004I7I.3 & $11 \mid 13$ & 1883 & All isoforms \\
\hline THBS4 & Hs00I7026I_ml & human & NM_003248.3 & $11 \mid 12$ & 1672 & All isoforms \\
\hline VIM & Hs00I85584_ml & human & NM_003380.3 & $2 \mid 4$ & 977 & All isoforms \\
\hline RPLPO & 433376 IF & human & NM_053275.3 & 3 & & \\
\hline GUSB & $4333767 F$ & human & NM_000I8I.I & $11 \mid 12$ & & \\
\hline AQP4 & Rn00563196_ml & rat & NM_00 I | $42366 . \mid$ & $2 \mid 3$ & 520 & 4 isoforms \\
\hline $\mathrm{DIO} 2$ & Rn0058|867_ml* & rat & NM_03|720.3 & $1 \mid 2$ & 777 & - \\
\hline GLUL/GS & Rn0|483I07_m|** & rat & NM_017073.3 & & 449 & - \\
\hline SLCIA2/ EAAT2 & Rn00568080_ml** & rat & NM_00 I035233.I & $9 \mid 10$ & 1526 & All isoforms \\
\hline THBS4 & Rn00574839_ml * & rat & NM_022547.I & & 2347 & 2 isoforms \\
\hline GAPDH & Rn0|462662_g | & rat & NM_01 7008.3 & & & \\
\hline PPIA & Rn03302269_gH & rat & NM_017I0I.I & & & \\
\hline
\end{tabular}


each subject and for each layer. cDNA was additionally preamplified by PCR (denaturing: $95^{\circ} \mathrm{C}$ for $10 \mathrm{~min}$, followed by 10 cycles at $95^{\circ} \mathrm{C}$ for $15 \mathrm{~s}$ and at $60^{\circ} \mathrm{C}$ for $4 \mathrm{~min}$ ) with the mix of TaqMan probes used in this study (Table 2) using TaqMan PreAmp Master Mix (Applied Biosystems).

The mRNA levels of selected astrocyte and glutamatergic markers were measured by qPCR using TaqMan MGB probes and primer sets (Table 2) using an ABI Prism $7900 \mathrm{HT}$ Sequence Detection System (all from Applied Biosystems). For relative quantification of mRNA expression, relative values of examined genes were calculated using the standard curve method, which were further normalized to the geometric means (GMs) of endogenous control genes as described previously (Dracheva et al, 2005). Three housekeeping genes (RPLPO, GUSB, and PPIA) (Tunbridge et al, 2010) were used as the endogenous references after testing them for expression stability using geNorm (http://medgen.ugent.be/ jvdesomp/genorm/).

\section{Neuroleptic-Treated Rats}

To assess the effects of neuroleptic exposure on the expression of target mRNAs (DIO2, AQP4, EAAT2, and GS), groups of six male Sprague-Dawley rats (6-8 months of age) received daily subcutaneous injections of haloperidol $(2 \mathrm{mg} / \mathrm{kg})$ or saline vehicle for 21 days. The specific haloperidol dosing parameters were selected because previous studies (Ritter and Meador-Woodruff, 1997) have shown them to be effective in regulating dopamine receptor mRNA expression in rat brain. Rats were killed by decapitation $24 \mathrm{~h}$ after the last injection and their brains were rapidly removed. Cortices were dissected and immediately frozen on dry ice. Gene expression for DIO2, AQP4, EAAT2, and GS was assessed as described above using identical procedures except that rat-specific probes were used.

\section{Analytical Approach}

Because of the technically challenging approach of LCM and microisolation of RNA, not all transcripts could be measured in all cases and cortical layers. Therefore, for layer-specific comparisons between specimens from persons with SZ and controls, $t$-tests were used to test for significance in mean expression levels. To test for differences in expression between the three different cortical layers (superficial (layers I-III), deep (layers IV-VI), and white matter underlying the anterior cingulate cortex), univariate and factorial ANOVAs with Tukey HSD analyses were used. We also determined the factorial relationship between the different astrocyte and glutamatergic markers using principal component analysis with varimax rotation. All analyses were carried out using Statistica (v9.1, StatSoft, Tulsa, OK).

\section{RESULTS}

\section{Schizophrenia}

In general, astrocyte and glutamate marker gene expression differences between persons with schizophrenia and comparison controls were infrequent in the superficial layers
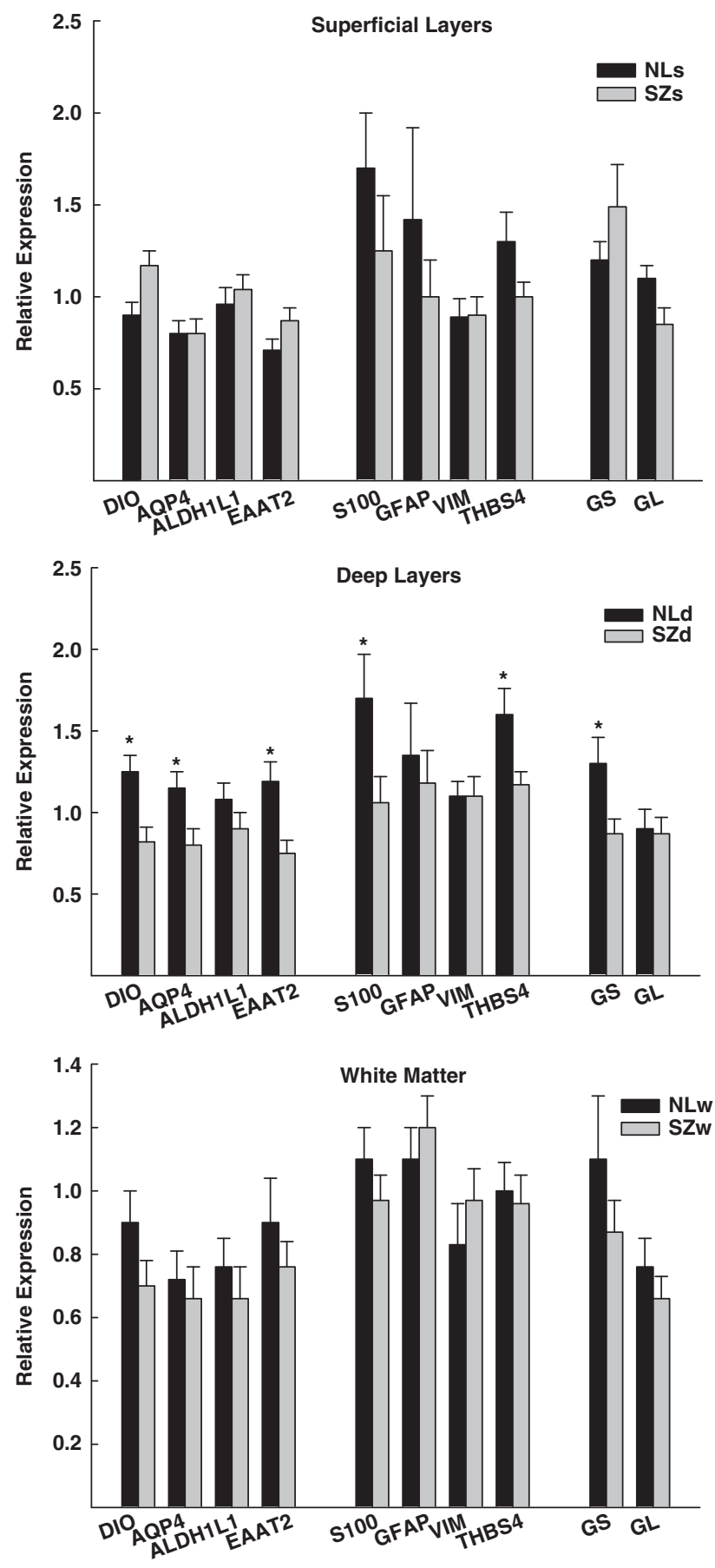

Figure I Relative gene expression levels of astrocyte-enriched and glutamate-related transcripts in the superficial (I-III), deep (IV-VI), and white matter layers of the anterior cingulate gyrus in persons with schizophrenia (SZ) and comparison controls (NL). The astrocyte and glutamate markers are grouped in accordance with the factor structure (I, II, and III, respectively) observed in the comparison controls. ( $P p<0.05 \mathrm{SZ}$ vs NL for each indicated transcript. DIO, diodinase type II; AQP4, aquaporin-4; ALDHILI, aldehyde dehydrogenase I family member LI; SI00, SI00 $\beta$; GFAP, glial fibrillary acidic protein; VIM, vimentin; THBS4, thrombospondin; GS, glutamine synthase; EAAT2, excitatory amino-acid transporter 2; and GL, glutaminase).

(layers I-III) or in the white matter immediately underlying the anterior cingulate cortex (Figure 1). On the other hand, expression of many of these same markers (DIO2, AQP4, 
THBS4, S100 $\beta$, GS, and EAAT2) was significantly ( $p$ s $<0.05$; S100 $\beta p=0.07$ ) reduced by $\sim 26-37 \%$ in the deep (layers IV-VI) laminae of the cingulate cortex of persons with SZ (Figure 1). These layer- and transcript-specific changes in gene expression were not influenced by the age of the subjects at the time of death or by brain $\mathrm{pH}$, as the groups did not differ significantly $(p s>0.3)$ from each other. In addition, the expression level of the different transcripts did not correlate significantly (except for $S 100 \beta$ and age; $\mathrm{r}=-0.31, p=0.02$ ) with these potentially confounding factors. The expression levels of DIO2, AQP4, EAAT2, and GS were unaffected in the cortices of rats treated for 3 weeks with haloperidol, with some transcripts showing nominally higher expression levels (AQP4 and GL) and others showing lower expression levels (DIO, ALDH1L1, and EAAT2) (all ps ranged between 0.06 and 0.9 ; nominal differences in expression level ranged between 0.75 and $12.5 \%$ ).

\section{Layer-Specific Expression of Astrocyte and Glutamate Transcripts}

To assess the distribution of the astrocyte and glutamate transcripts independently of the changes associated with SZ, we analyzed the data derived from the unaffected comparison group only. In general, the layer-specific expression of these transcripts fell into two categories: one in which the expression of the transcript was significantly higher in the deep layers of the cingulate cortex, and the other in which the expression of the transcript was more uniform across the layers and the white matter. The expression of DIO2, AQP4, EAAT2, and THBS4 followed an inverted V-shaped pattern in which the expression level of the transcript was highest in the deep layers of the anterior cingulate cortex (Fs > 3.63, ps<0.05). Nominally, the expression of ADLH1L1 followed a similar pattern, but the differences between layers were not statistically significant $(\mathrm{F}=2.2$, $p=0.12$ ). The expression patterns of GS, GFAP, $\mathrm{S} 100 \beta$, VIM, and GL across the different laminae were not significantly different from each other $(p s>0.05)$.

\section{Principal Component Analysis of Astrocyte and Glutamate Gene Expression}

To determine whether the expression of astrocyte- and glutamate-associated gene expression in the layers examined could be grouped into factors with common variance, principal component analysis was performed. In the comparison control group, the markers grouped readily into three factors that cumulatively accounted for $69.1 \%$ of the variance. Factor 1 was comprised of DIO2, AQP4, ALDH1L1, and EAAT2 (33.3\% of variance). Factor 2 included S100 $\beta$, GFAP, VIM, and THBS $4(27.8 \%$ of variance) and factor 3 included GA and GS (13.6\% of variance). The factorial distribution of markers for persons with schizophrenia was essentially identical to that of the controls, except that GS entered factor 1 with minimal loading on factor 3.

\section{DISCUSSION}

Several novel observations emerge from the current analyses. The results provide relatively clear evidence supporting previous findings (Steffek et al, 2008) of abnormal and reduced expression of glutamate synthase in schizophrenia and localize this reduction in GS gene expression to the deep layers of the anterior cingulate cortex. They also establish that a similar reduction occurs in the expression of EAAT2, one of the two glial transporters of glutamate (Bauer et al, 2010; Lauriat et al, 2006; Huerta et al, 2006; Yang et al, 2009), but once again this reduction is confined to the deep layers of the anterior cingulate gyrus and spares the more superficial layers and the underlying white matter. The results also show that there is a concomitant, predominantly deep layer-specific reduction in the mRNA expression of astrocyte markers, but that this reduction is not uniform, applying to only some astrocyte markers (diodinase type II, aquaportin-4, S100 $\beta$, glutamine synthase, EAAT2, and thrombospondin-4) and not to others (aldehyde dehydrogenase 1 family member L1, glial fibrillary acidic protein, and vimentin). These observations suggest that astrocyte-associated glutamate uptake and glutamine-converting enzyme abnormalities of the cingulate cortex are likely confined to the microenvironment of neurons with subcortical and intracortical projections (Mountcastle, 1997). It is noteworthy that the deep cortical layer specificity of these results is consistent with a recent microarray study (Arion et al, 2010) that also pointed to the significantly greater gene expression vulnerability of the infragranular layers of the frontal cortex in persons with SZ. That SZ-associated abnormalities are more pronounced in the infragranular layers of the frontal cortex is perhaps not surprising, given that these deep layers represent points of convergence for projections from more superficial layers, as well as those originating subcortically from structures, such as the thalamus (Watts and Thomson, 2005). Notably, there is substantial evidence for glutamatergic abnormalities associated with thalamic projections into the deep layers of the anterior cingulate gyrus (Clinton and MeadorWoodruff, 2004).

A parsimonious interpretation of the results summarized above is a reduction in the numbers of some population(s) of astrocytes localized to the deep layers of the anterior cingulate gyrus in SZ and the sparing of these astrocytes in the superficial layers and its underlying white matter. Reductions in the expression of this same population of astrocytes may be the source of the reduced expression of the astrocyte-specific glutamate transporter (EAAT2) and the glutamate-to-glutamine-converting enzyme glutaminase. Of course it is possible, indeed equally plausible, that the detected SZ-specific changes are not a result of reduced numbers of astrocytes, but rather a reduction or a downregulation of the expression of these mRNAs. More detailed quantitative anatomical studies will be required to distinguish between these two possibilities.

The possibility that the astrocyte-enriched transcripts studied represent at least two distinct populations of glia with distinct transcriptome profiles is supported by the pattern of distribution of the expression levels of the different markers (i.e, approximately equal expression levels of GS, GFAP, S100 $\beta$, and VIM in the white matter and the two gray matter subdivisions dissected $v s$ higher levels of expression of DIO2, AQP4, EAAT2, and THBS4 in deep cortical layers relative to the underlying white matter and superficial layers). With the exception of the expression 
pattern of thrombospondin-4, the likelihood of such a distinction was supported by the principal component analysis that suggested that the variance in the expression levels of these transcripts could be explained by two factors, one including DIO2, AQP4, ALDH1L1, and EAAT2 and the other subsuming S100 $\beta$, GFAP, VIM, and THBS4.

That several distinct populations of astrocytes, including protoplasmic and fibrous, exist in the brain has been known for many years (Swanson et al, 2004). Protoplasmic astrocytes express low levels of GFAP and are therefore not often detected with GFAP-based immunohistochemical techniques (Swanson et al, 2004). Recent transcriptomebased studies and observations in ALDH1L1-tagged mice have suggested that astrocytes are significantly more numerous in the brain than previously suspected or revealed by GFAP staining and rival neurons in their diversity, gene expression patterns, and distribution within the brain (Barres, 2008; Zhang and Barres, 2010; Cahoy et al, 2008). The results presented in this study clearly document the differential expression of diverse astrocyte-enriched genes within the superficial and deep layers of the anterior cingulate gyrus and its underlying white matter. These results also suggest that the transcriptional profile of different astrocytes may be different such that, in one or some subtypes, the expression levels of DIO2, AQP4, ALDH1L1, and THBS4 mRNAs are interrelated, whereas in other subtypes interrelationships are highest for the expression of GFAP, S100 $\beta$, and VIM. As GFAP is most prominently expressed in fibrous astrocytes (Swanson et al, 2004), it is tempting to speculate that the subtype(s) in which DIO2, AQP4, ALDH1L1, and THBS4 factor together represent enrichment in protoplasmic astrocytes, whereas the second class in which GFAP, S100 $\beta$, and VIM factor together represents fibrous astrocytes more closely. Most of the astrocyte markers, the expression of which was reduced in persons with SZ (DIO2, AQP4 and THBS4), belong to those in the first factor, possibly protoplasmic astrocytes, and are most highly expressed in the deep layers of the cingulate gyrus in unaffected controls. However, the gene expression changes in SZ did not correspond exactly to the factor structure observed, suggesting more complex interactions of gene expression, cytoarchitecture, and disease. Among the numerous possibilities are (a) the strong possibility that the morphological distinctions currently recognized do not fully represent the spectrum of astrocyte heterogeneity (Zhang and Barres, 2010); or (b) the similarly strong possibility that the microenvironment of the different layers of the cortex in health and disease influences the profile of genes expressed by astrocytes. Distinguishing between these and other plausible, non-mutually exclusive, and complex possibilities requires more detailed experimentation.

As is typical of postmortem studies of SZ, it is possible that the reduced expression of DIO2, AQP4, THBS4, S100 $\beta$, GS, and EAAT2 in SZ was due to the chronic and prolonged exposure of these individuals to antipsychotic medications. Medication effects cannot be readily ruled out in postmortem studies of SZ; however, in the current study these effects would have to be confined to cells located in the deep layers of the cingulate gyrus and not to those in the superficial layers or in the underlying white matter. It is also noteworthy that in a previous western blot-based study of
GS and GFAP expression (Steffek et al, 2008), the chronic treatment of rats with $1 \mathrm{mg} / \mathrm{kg}$ per day of haloperidol for 4 weeks did not significantly effect GS and GFAP protein expression levels and in the current study 3-week treatment of rats with even higher doses of haloperidol $(2 \mathrm{mg} / \mathrm{kg}$ per day) was without significant effect on the astrocyte markers studied. It is important to note, however, that cortical specimens from the rats were not subjected to LCM, making it possible that laminar effects of haloperidol treatment were obscured by the inclusion of superficial layers in the same assay.

\section{ACKNOWLEDGEMENTS}

Supported by: MH064673, VA-Merit, and VA-MIRECC.

\section{DISCLOSURE}

The authors declare no conflict of interest.

\section{REFERENCES}

Arion D, Horvath S, Lewis DA, Mirnics K (2010). Infragranular gene expression disturbances in the prefrontal cortex in schizophrenia: signature of altered neural development? Neurobiol Dis 37: 738-746.

Arnold SE, Franz BR, Trojanowski JQ, Moberg PJ, Gur RE (1996). Glial fibrillary acidic protein-immunoreactive astrocytosis in elderly patients with schizophrenia and dementia. Acta Neuropathol (Berl) 91: 269-277.

Arnold SE, Trojanowski JQ, Gur RE, Blackwell P, Han LY, Choi C (1998). Absence of neurodegeneration and neural injury in the cerebral cortex in a sample of elderly patients with schizophrenia. Arch Gen Psychiatry 55: 225-232.

Barradas PC, Ferraz AS, Ferreira AA, Daumas RP, Moura EG (2000). 2' $3^{\prime}$ Cyclic nucleotide $3^{\prime}$ phosphodiesterase immunohistochemistry shows an impairment on myelin compaction in hypothyroid rats. Int J Dev Neurosci 18: 887-892.

Barres BA (2008). The mystery and magic of glia: a perspective on their roles in health and disease. Neuron 60: 430-440.

Bauer D, Gupta D, Harotunian V, Meador-Woodruff JH, McCullumsmith RE (2008). Abnormal expression of glutamate transporter and transporter interacting molecules in prefrontal cortex in elderly patients with schizophrenia. Schizophr Res 104: 108-120.

Bauer D, Gupta D, Haroutunian V, Meador-Woodruff JH, McCullumsmith RE (2010). Abnormal glycosylation of EAAT1 and EAAT2 in prefrontal cortex of elderly patients with schizophrenia. Schizphr Res 117: 92-98.

Benes FM, Bird ED (1987). Spatial arrangement of neurons in cingulate cortex of schizophrenics. Arch Gen Psychiatry 44: 608-616.

Bernstein HG, Steiner J, Bogerts B (2009). Glial cells in schizophrenia: pathophysiological significance and possible consequences for therapy. Expert Rev Neurother 9: 1059-1071.

Bruneau EG, McCullumsmith RE, Haroutunian V, Davis KL, Meador-Woodruff JH (2005). Increased expression of glutaminase and glutamine synthetase mrna in the thalamus in schizophrenia. Schizophr Res 75: 27-34.

Byne W, Dracheva S, Chin B, Schmeidler JM, Davis KL, Haroutunian V (2008). Schizophrenia and sex associated differences in the expression of neuronal and oligodendrocyte specific genes in individual thalamic nuclei. Schizo Res 98: $118-128$. 
Cahoy JD, Emery B, Kaushal A, Foo LC, Zamanian JL, Christopherson KS et al (2008). A transcriptome database for astrocytes, neurons, and oligodendrocytes: a new resource for understanding brain development and function. J Neurosci 28: 264-278.

Clinton SM, Meador-Woodruff JH (2004). Thalamic dysfunction in schizophrenia: neurochemical, neuropathological, and in vivo imaging abnormalities. Schizophr Res 69: 237-253.

Davidson M, Harvey PD, Powchik P, Parrella M, White L, Knobler HY et al (1995). Severity of symptoms in chronically institutionalized geriatric schizophrenic patients. Am J Psychiatry 152: 197-207.

Dracheva S, Byne W, Chin B, Haroutunian V (2008). Ionotropic glutamate receptor mRNA expression in the human thalamus: Absence of change in schizophrenia. Br Res 1214: 23-34.

Dracheva S, Marras SA, Elhakem SL, Kramer FR, Davis KL, Haroutunian V (2001). N-methyl-D-aspartic acid receptor expression in the dorsolateral prefrontal cortex of elderly patients with schizophrenia. Am J Psychiatry 158: 1400-1410.

Dracheva S, McGurk SR, Haroutunian V (2005). mRNA expression of AMPA receptors and AMPA receptor binding proteins in the cerebral cortex of elderly schizophrenics. J Neurosci Res 79: 868-878.

Falke E, Han LY, Arnold SE (2000). Absence of neurodegeneration in the thalamus and caudate of elderly patients with schizophrenia. Psychiatry Res 93: 103-110.

Gluck MR, Thomas RG, Davis KL, Haroutunian V (2002). Implications for altered glutamate and GABA metabolism in the dorsolateral prefrontal cortex of aged schizophrenic patients. Am J Psychiatry 159: 1165-1173.

Halassa MM, Fellin T, Haydon PG (2007). The tripartite synapse: roles for gliotransmission in health and disease. Trends Mol Med 13: $54-63$

Haroutunian V, Katsel P, Dracheva S, Stewart DG, Davis KL (2007). Variations in oligodendrocyte-related gene expression across multiple cortical regions: implications for the pathophysiology of schizophrenia. Int $J$ Neuropsychopharmacol 10: 565-573.

Harrison PJ, Weinberger DR (2004). Schizophrenia genes, gene expression, and neuropathology: on the matter of their convergence. Mol Psychiatry 10: 40-68.

Harvey PD, Howanitz E, Parrella M, White L, Davidson M, Mohs $\mathrm{RC}$ et al (1998). Symptoms, cognitive functioning, and adaptive skills in geriatric patients with lifelong schizophrenia: a comparison across treatment sites. Am J Psychiatry 155: 1080-1086.

Haznedar MM, Buchsbaum MS, Hazlett EA, Shihabuddin L, New A, Siever LJ (2004). Cingulate gyrus volume and metabolism in the schizophrenia spectrum. Schizophr Res 71: 249-262.

Huerta B, McCullumsmith RE, Haroutunian V, Gimenez-Amaya JM, Meador-Woodruff JH (2006). Expression of excitatory amino acid transporter interacting protein transcripts in the thalamus in schizophrenia. Synapse 59: 394-402.

Javitt DC (2007). Glutamate and schizophrenia: phencyclidine, Nmethyl-D-aspartate receptors, and dopamine-glutamate interactions. Int Rev Neurobiol 78: 69-108.

Kenakin T (2002). Drug efficacy at G protein-coupled receptors. Annu Rev Pharmacol Toxicol 42: 349-379.

Krystal JH, Moghaddam B, Breier A, Goldman-Rakic PS, McElvey J (1998). Glutamate, dopamine, the frontal cortex, and schizophrenia. Biol Psychiatry 43: 60S.
Lauriat TL, Dracheva S, Chin B, Schmeidler J, McInnes LA, Haroutunian V (2006). Quantitative analysis of glutamate transporter mRNA expression in prefrontal and primary visual cortex in normal and schizophrenic brain. Neuroscience 137: 843-851.

Mirra SS, Heyman A, McKeel D, Sumi SM, Crain BJ, Brownlee LM et al (1991). The consortium to establish a registry for Alzheimer's disease (CERAD). Part II. Standardization of the neuropathologic assessment of Alzheimer's disease. Neurology 41: 479-486.

Mountcastle V (1997). The columnar organization of the neocortex. Brain 120: 701-722.

Purohit DP, Perl DP, Haroutunian V, Powchik P, Davidson M, Davis KL (1998). Alzheimer disease and related neurodegenerative diseases in elderly patients with schizophrenia: a postmortem neuropathologic study of 100 cases. Arch Gen Psychiatry 55: 205-211.

Ritter LM, Meador-Woodruff JH (1997). Antipsychotic regulation of hippocampal dopamine receptor messenger RNA expression. Biol Psychiatry 42: 155-164.

Schnieder TP, Dwork AJ (2011). Searching for neuropathology: gliosis in schizophrenia. Biol Psychiatry 69: 134-139.

Steffek AE, McCullumsmith RE, Haroutunian V, Meador-Woodruff JH (2008). Cortical expression of glial fibrillary acidic protein and glutamine synthetase is decreased in schizophrenia. Schizo Res 103: 71-82.

Steiner J, Bernstein HG, Bielau H, Farkas N, Winter J, Dobrowolny $\mathrm{H}$ et al (2008). S100B-immunopositive glia is elevated in paranoid as compared to residual schizophrenia: a morphometric study. J Psychiatr Res 42: 868-876.

Stevens CD, Altshuler LL, Bogerts B, Falkai P (1988). Quantitative study of gliosis in schizophrenia and Huntington's chorea. Biol Psychiatry 24: 697-700.

Stevens JR (1982). Neuropathology of schizophrenia. Arch Gen Psychiatry 39: 1131-1139.

Swanson RA, Ying W, Kauppinen TM (2004). Astrocyte influences on ischemic neuronal death. Curr Mol Med 4: 193-205.

Toro CT, Hallak JE, Dunham JS, Deakin JF (2006). Glial fibrillary acidic protein and glutamine synthetase in subregions of prefrontal cortex in schizophrenia and mood disorder. Neurosci Lett 404: 276-281.

Tunbridge EM, Eastwood SL, Harrison PJ (2010). Changed relative to what? Housekeeping genes and normalization strategies in human brain gene expression studies. Biol Psychiatry 69: 173-179.

Wang L, Metzak PD, Honer WG, Woodward TS (2010). Impaired efficiency of functional networks underlying episodic memoryfor-context in schizophrenia. J Neurosci 30: 13171-13179.

Watts J, Thomson AM (2005). Excitatory and inhibitory connections show selectivity in the neocortex. J Physiol 562: 89-97.

Webster MJ, O'Grady J, Kleinman JE, Weickert CS (2005). Glial fibrillary acidic protein mRNA levels in the cingulate cortex of individuals with depression, bipolar disorder and schizophrenia. Neuroscience 133: 453-461.

Yang Y, Gozen O, Watkins A, Lorenzini I, Lepore A, Gao Y et al (2009). Presynaptic regulation of astroglial excitatory neurotransmitter transporter GLT1. Neuron 61: 880-894.

Zhang Y, Barres BA (2010). Astrocyte heterogeneity: an underappreciated topic in neurobiology. Curr Opin Neurobiol 20: $588-594$. 